\title{
A New Locality for the Elusive and Endemic Yellow-Spotted Wolf Snake (Lycodon flavomaculatus Wall 1907), with Notes on Distribution and Habitat
}

\author{
Vivek Sharma ${ }^{1}$, Arpit Jain ${ }^{2}$, and Rita Bhandari ${ }^{3}$ \\ 'Department of Zoology, Government Model Science College, Jabalpur (Madhya Pradesh) 482003, India (vrks1007@gmail.com) \\ 285/2, Shishak Nagar, Airport Road, Indore (Madhya Pradesh) 452005, India (lycodon.aj@gmail.com) \\ ${ }^{3}$ Department of Zoology, Government O.F.K. College, Jabalpur (Madhya Pradesh) 482003, India (ritabhandari06@yahoo.com)
}

Seven species of Wolfsnakes (Lycodon Boie 1827) occur

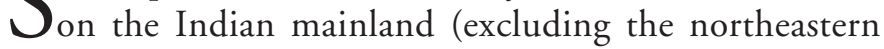
region): Common Wolfsnake (L. aulicus Linnaeus 1758), Yellow-collared Wolfsnake (L. flavicollis Mukherjee and Bhupathy 2007), Yellow-spotted Wolfsnake (L. flavomaculatus Wall 1907), Twin-spotted Wolfsnake (L. jara Shaw 1802), Mackinnon's Wolfsnake (L. mackinnoni Wall 1906), Northern Wolfsnake (L. striatus Shaw 1802), and Travancore Wolfsnake (L. travancoricus Beddome 1870). The natural history and geographical distribution of the Yellow-Spotted Wolfsnake (L. flavomaculatus) are much in need of further investigation. Since the initial description, no significant study has been undertaken on this species, although Captain (1999) addressed issues related to identification.

Wall (1907) first recognized Lycodon flavomaculatus as a distinct species. Previously, Boulenger (1893) had considered it a mere color variant of $L$. aulicus. Wall (1907) himself regarded initially deposited specimens as color variants of $L$. jara until he received a live specimen representing a specific population from "Dharwar" (= Dharwad, Karnataka, India), which is the type locality of $L$. flavomaculatus. Additionally, he mentioned other important localities, which included Sangli, "Kirkee" (= Khadki), "Poona" (= Pune District), "Nasik" (= Nashik District of Maharashtra), and "Fyzabad" (= Faizabad District of Uttar Pradesh). Recently, Wallach et al. (2014) treated Fyzabad as an invalid type locality. Still, this species has been reported with confidence from at least four states (Faizabad, Uttar Pradesh is yet in question), which include the following localities with districts referring to the smallest unit of each locality: Dharwad of Karnataka (Wall 1907), Sangli, Pune, and Nashik (Wall 1907); Buldhana and Vidarbha (Wall 1923); Amravati, including Melghat (Pradhan 2005; Nande and Deshmukh 2007); Raigarh (Walmiki et al. 2011); Satara (Chikane and Bhosale 2012);
Solapur (Srinivasulu et al. 2014) and Nagpur (Deshmukh et al. 2015) of Maharashtra; Bhanvagar and Vadodara (Vyas and Upadhaya 2008) of Gujarat. Srinivasulu et al. (2014) tabulated (p. 28) three additional localities from Madhya Pradesh (Balaghat and Mandla) and Chattisgarh (Sarguja) in a personal communication to Sanjay Thakur. However, in another part of the document (p. 55), the same species was treated as endemic to the Western Ghats and mentioned central Indian localities as unconfirmed. Despite having contradictory information, we list two localities in Madhya Pradesh (Balaghat and Mandla), as they are neighboring regions of documented localities for $L$. flavomaculatus. We express our doubts on the validity of Sarguja, Chattisgarh, which is far from the known distribution and lacks even photographic evidence; $S$. Thakur (pers. comm.) agreed. Apart from these, Murthy (1991) presented evidence for the presence of L. flavomaculatus in the Nilgiri Biosphere Reserve, Tamil Nadu, but these snakes were later shown to be L. flavicollis based on the original description by Mukherjee and Bhupathy (2007). Also, one of the early reports of $L$. flavomaculatus from Fyzabad (= Faizabad of Uttar Pradesh) is either disregarded by the majority of subsequent workers or discussed as "Oudi" (= Awadh?), a term used to cover a large geographical area. At this time, we refrain from commenting on the validity of that locality and leave this question to future investigators.

On 6 and 9 September 2013, we captured two live L. flavomaculatus within $500 \mathrm{~m}$ of one another in the vicinity of the city of Vidisha, Madhya Pradesh, India $\left(23.31^{\circ} \mathrm{N}, 77.49^{\circ} \mathrm{E}\right.$, $427 \mathrm{asl}$ ). We encountered the first individual at $2100 \mathrm{~h}$ on the first floor at a height of $4.2 \mathrm{~m}$ in an unused old building. We collected the other individual at $2145 \mathrm{~h}$ crossing an open grassy plain with scattered medium-sized rocks adjacent to an agricultural area. We took morphological data from both specimens and released them at the original sites of capture. 


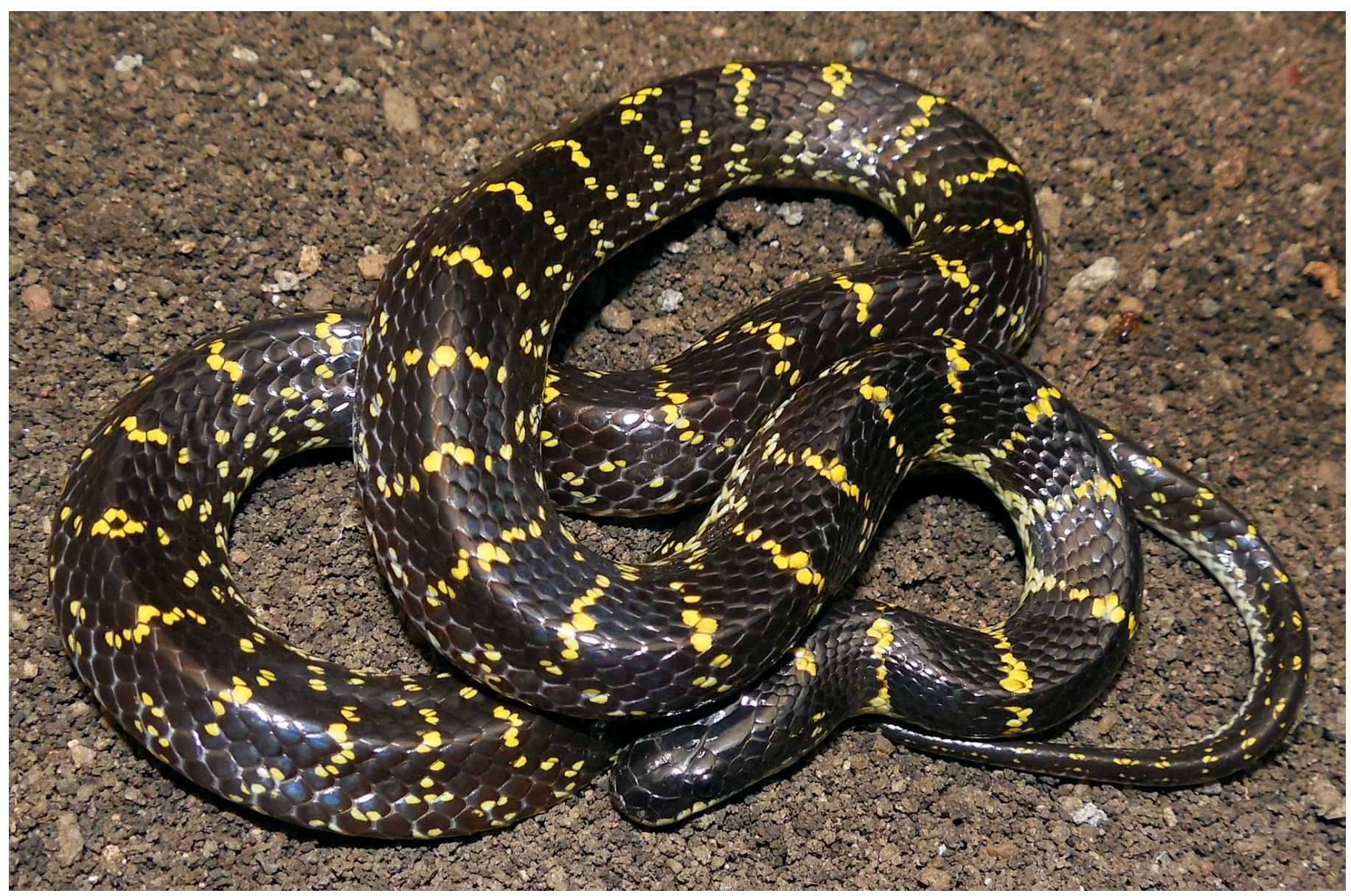

Fig. 1. A Yellow-Spotted Wolfsnake (Lycodon flavomaculatus) encountered at $2100 \mathrm{~h}$ on the first floor at a height of $4.2 \mathrm{~m}$ in an unused old building in the outskirts of Vidisha, Madhya Pradesh, India. Photograph by Arpit Jain.

The two unsexed adults (Fig. 1) exhibited the following characters: Length 520 and $410 \mathrm{~mm}$, respectively; head depressed, clearly broader than neck; 9 supralabials, 3 rd to 5 th in contact with orbit; lower edge of both nasals covered by 1 st supralabial; 1 well-defined loreal in contact with internasals on each side; 1 preocular; 2 postoculars; temporals $2+3$; smooth dorsal scales in 17:17:15 rows; ventrals 168 and 180, respectively; cloacal divided; paired subcaudals 57 and 59, respectively. Head patternless, glossy brownish-black with yellowish-white lips; dorsum glossy brownish-black with a middorsal row of vibrant yellow buttercup-shaped spots extending from neck to tip of tail and aligned with discontinuous crossbands of yellow-white color extending onto flanks; venter glossy white with grayish outer margins on each ventral.

Vidisha is at an average elevation of $424 \mathrm{~m}$ in the Vindhya Mountain Range of the Central Indian Highlands. It is located $290 \mathrm{~km}$ north of the nearest known locality for L. flavomaculatus at Amravati in Maharashtra and about 307 $\mathrm{km}$ northwest of another known site in Balaghat in Madhya Pradesh. The land in the area is on a plain of mixed black soil with scattered medium-sized rocks and stones. During most months of the year, this type of soil is dry and develops cracks sufficiently deep to provide refugia for small burrowing rep- tiles and other animals. The habitat extends throughout the city and into nearby rural and agricultural areas.

By updating our knowledge of the distribution of $L$. flavomaculatus, now known to cover most of the Deccan Plateau (especially the north-central portions), the semi-arid zone of northwestern India (in Gujarat), and parts of the Central Indian Highlands, we can begin to draw some conclusions regarding the habitat of the species. With a total of 15 or 16 acknowledged locations, we see no correlation between the range of the species and the Western Ghats. The localities of Dharwad, Sangli, and Satara are situated at the eastern edge of the Western Ghats, a region laying largely in the rainshadow of the Western Ghats and characterized by low rainfall, a less humid climate, and a largely xeric-adapted flora. Similarly, other localities in Maharashtra (Amravati, Nashik, Pune, Buldhana, Raigarh, Sholapur, and Nagpur) and those in Gujarat, Madhya Pradesh, and even the questionable locality in Chattisgarh are known for a relatively dry climate and semi-scrub or dry-deciduous forest. Consequently, we conclude that the species is most abundant in dry grasslands or on plateaus at low or moderate elevations, as opposed to the higher elevations of the Western Ghats that are subjected to at least seasonally heavy rainfall. Although most references to the 


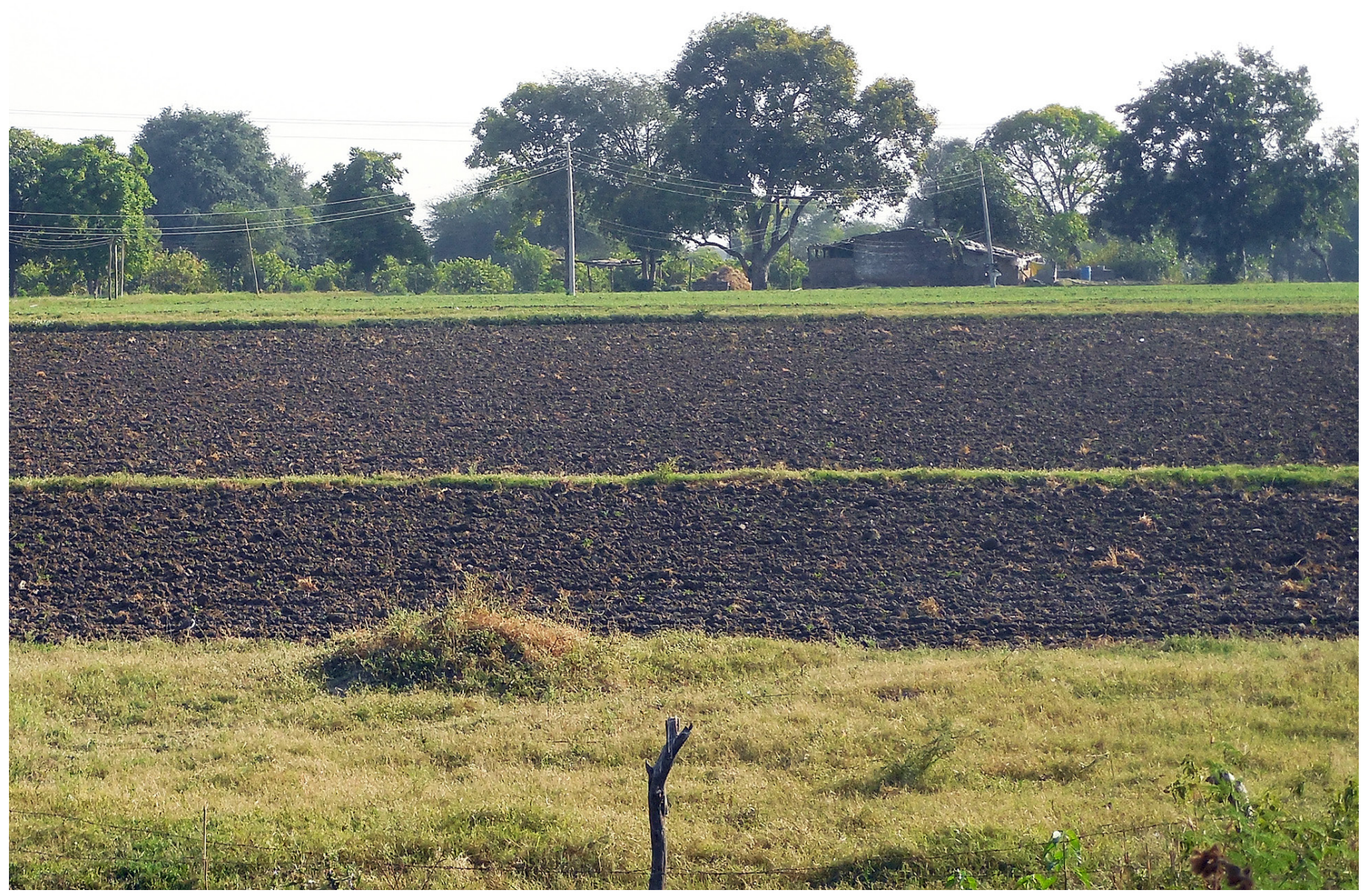

Fig. 2. Habitat of the Yellow-Spotted Wolfsnake (Lycodon flavomaculatus) from the outskirts of Vidisha, Madhya Pradesh, India. Photograph by Arpit Jain.

species associate it with the Western Ghats and surroundings, the distribution of this species is largely restricted to the eastern edge of the Western Ghats and extends to a much wider area of north-central India with comparatively little rainfall, low humidity, and generally drier climates. That the species' range extends above the Gangetic Plains and into the Thar Desert seems unlikely.

The macrohabitat of L. flavomaculatus appears to consist primarily of rocky terrain within semi-scrub, grasslands, unused agricultural lands, and dry deciduous forests. As is documented for other Indian species of Lycodon and clearly indicated by our discovery of a snake in an abandoned building, this species readily exploits urban environments and often is encountered in houses or other human structures. Other aspects of the natural history of L. flavomaculatus remain largely unknown and considerable work remains in order to fill remaining gaps in its known range and determine whether its distribution extends farther into northern and eastern India.

\section{Acknowledgements}

Our sincere thanks to Aaron Bauer for providing access to rare literature. We thank Gernot Vogel for many valuable comments on earlier drafts of this manuscript; Aditya Kshirsagar, Amit Sayyed, and Vishal Prasad for constructive discussions on habitat types; and Sanjay Thakur for informative conversations about localities in central India.

\section{Literature Cited}

Boulenger, G.A.1893. Catalogue of the Snakes in the British Museum (Natural History) I. Taylor \& Francis, London.

Captain, A. 1999. On the identification of Lycodon flavomaculatus Wall 1907. Journal of the Bombay Natural History Society 96:323-327.

Chikane, S. and H.S. Bhosale. 2012. Reptiles of Kaas, Northern Western Ghats, Maharashtra, India, with notes on habitat preferences, abundances and threats. Sauria 34(3):3-15.

Deshmukh, R.V., S.A, Deshmukh, and S.A. Badekar. 2015. Rescued records of snakes from Nagpur District, Maharashtra with data on unrecorded species. Reptile Rap 17:34-43.

Mukherjee, D. and S. Bhupathy. 2007. A new species of Wolf Snake (Serpentes: Colubridae: Lycodon) from Anaikatti Hills, Western Ghats, Tamil Nadu, India. Russian Journal of Herpetology 14:21-26.

Murthy, T.S.N. 1991. A rare Wolf Snake, Lycodon flavomaculatus, from the Nilgiri Biosphere Reserve, South India. The Snake 23:104-106.

Nande, R. and S. Deshmukh. 2007. Snakes of Amravati District including Melghat, Maharashtra, with important record of the Indian Egg-eater, Montane Trinket Snake and Indian Smooth Snake. Zoos' Print Journal 22:2920-2924.

Pradhan, M.S. 2005. Reptilia. Fauna of Melghat Tiger Reserve, Conservation Area Series 24:165-221.

Smith, M.A. 1943. The Fauna of British India, Ceylon and Burma, Including the Whole of the Indo-Chinese Sub-Region. Reptilia and Amphibia. Volume IIISerpentes. Taylor and Francis, London. 
Srinivasulu, C., B. Srinivasulu, and S. Molur 2014. The Status and Distribution of Reptiles in the Western Ghats, India. Conservation Assessment and Management Plan (CAMP). Wildlife Information Liaison Development Society, Coimbatore, Tamil Nadu.

Vyas, R.V. and K. Upadhaya. 2008. On the occurrence of Lycodon flavomaculatus Wall, 1907 in Gujarat State, India. Sauria 30(1):55-58.

Wall, F. 1907. Some new Asian snakes. Journal of the Bombay Natural History Society 17:612-618.

Wall, F. 1923. A hand-list of the snakes of the Indian Empire, Part 2. Journal of the
Bombay Natural History Society 29:598-632.

Wallach, V., K.L. Williams, and J. Boundy. 2014. Snakes of the World: A Catalogue of Living and Extinct Species. CRC Press, Boca Raton, Florida.

Walmiki, N., D. Karangutkar, A. Jadhav, S. Parab, and N.S. Achyuthan. 2011. First record of Yellow-spotted Wolf Snake Lycodon flavomaculatus (Wall, 1907) from Chirner Forest, Uran, Maharashtra. Reptile Rap 12:2-3.

Whitaker, R. and A. Captain. 2004. Snakes of India. The Field Guide. Draco Books, Chennai, India. 